\title{
Regional guidelines for flood risk assessment and emergency response: participatory approach and IT tools for risk management.
}

\author{
Tiziana Bisantino ${ }^{1, a}$, Giuseppe Falcone ${ }^{2}$, Franco Intini ${ }^{1}$, Antonio Mario Lerario ${ }^{1}$, Pierluigi Loiacono ${ }^{1}$, Apollonia Netti $^{2}$ \& \\ Francesco Vito Ronco ${ }^{1}$ \\ ${ }^{1}$ Puglia Region Civil Protection Section, Modugno (BA) 70026, Italy. \\ 2 Servizi di Informazione Territoriale S.r.I. Noci (BA) 70015, Italy.
}

\begin{abstract}
Puglia Region has issued, under the "2014-2020 National Governance and Institutional Capacity Operational Program", the "Regional Guidelines for Municipal Civil Protection Plans" in order to improve risk management for civil protection purposes. In the drafting process of the Guidelines the regional Civil Protection has involved n. 5 pilot municipalities characterized by different flood event scenario, typical of the regional context: water courses downstream of artificial reservoirs, river basins, ephemeral streams in karst environment, endoreic river systems and torrential streams. The municipalities have tested the tools and data sheets, providing feedback and useful information to build an instrument calibrated to the real needs of the territory. The outcome of the work is a document that methodically guides the municipalities in the collection and systematization of information, giving them the possibility to implement and integrate the Plans over time, thanks to a structure divided into macro-sections, sections and modules linked together but independent of one another.
\end{abstract}

\section{The evolution of Civil Protection Planning}

In Italy, Civil Protection is not a task assigned to a single administration, but a function attributed to an integrated system: the National Civil Protection Service, established in 1992 by Law no. 225. The law, for the first time, introduced the provincial Emergency Planning and the municipal Civil Protection structures.

In 1998 the Legislative Decree n. 112 transferred part of the Civil Protection responsibilities from State to Regions and Municipalities and attributed to Municipalities the functions relating to the preparation of Municipal and/or Inter-municipal Emergency Plans.

Following the calamitous events that occurred in May 1998 in five Municipalities of Campania region, the law $n$. 267 of 1998, introduced in the emergency plans measures for first interventions, assistance to the population, safety checks including early warning by means of monitoring systems for hydrogeological risk in those areas where the great vulnerability of the territory is linked to dangers for people, things and environment.

In 2012 the law n. 100 established that plans and programs for the management, protection and rehabilitation of the territory must be coordinated with the Civil Protection emergency plans, introducing in this way a principle of fundamental importance: the need for coordination among urban planning tools, protection and management of the territory and Civil Protection planning.
Currently, the Legislative Decree n. 1 of 2018 "Civil Protection Code", states that the Civil Protection planning activity is a fundamental function of the Municipalities and, in order to effectively disseminate knowledge of the plan to the population, citizen's participation in its implementation must be envisaged.

\section{Regional Guidelines for Municipal Civil Protection Plans}

\subsection{Guidelines structure}

In order to ensures a homogeneous and unitary Civil Protection planning at regional level, a complete collection of procedures and information of each municipality that can be quickly interpreted and understood by all end-users, the Civil Protection of the Puglia region draw up the regional Guidelines and developed IT tools for drafting Municipal Civil Protection Plans.

The Guidelines are divided into 5 macro-sections that correspond to the structure of the Plan (fig. 1). Each macro-section is divided into sections and modules that are connected but independent of one another, to allow easy updating whenever advances in the state of knowledge, technical-scientific insights or organizational changes occur.

\footnotetext{
${ }^{a}$ Corresponding author: t.bisantino@regione.puglia.it

DOI 10.3311/FLOODRisk2020.18.3
} 


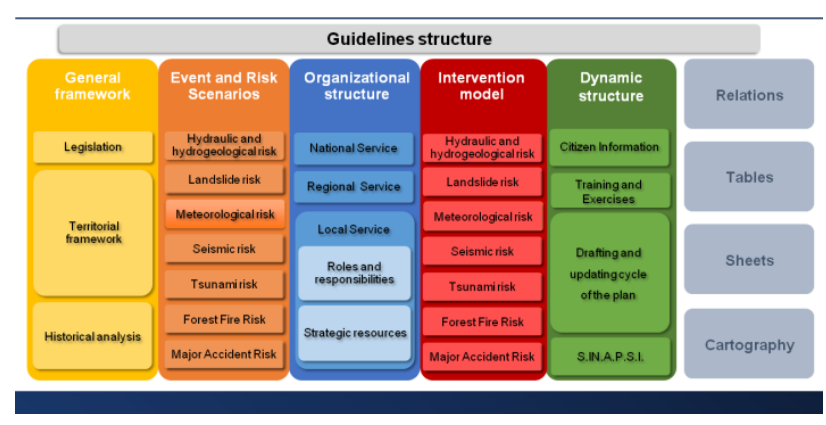

Figure 1. Guidelines structure

The general framework represents the preparatory part of the Plan and contains the legislative framework, all the information regarding territorial and environmental aspects as well as a historical overview of the calamitous events that occurred in that area.

The event scenario is the evolution in space and time of the expected event, in its completeness and complexity. It quantitatively describes the phenomena that may occur and their main characteristics (vulnerable areas, intensity, direction of propagation and singular points where the phenomenon triggers or can undergo significant evolutions).

The Risk Scenario is defined as the evolution in space and time of the event and its effects, taking into account the distribution of the estimated exposed, their vulnerability and the mitigation actions.

The organizational structure describes how the Civil Protection System is composed at the different levels (national, regional, local) and how the municipal level respond to the emergency, in terms of number, type and organization of men, materials and resources, organization of the Municipal Operational Centre, the support functions, the structures and strategic areas and the territorial monitoring activities.

The intervention model is the operational part of the Plan and must be schematic, clear and exhaustive. By systemizing all the information relating to the general framework, the risk scenarios, the organizational structure and the warning system, it defines the actions to be activated for each operational phase, assigns the decision making responsibilities to the various levels of command and control, uses the resources in a rational manner, defines a communication system which allows a constant exchange of information within the Civil Protection System and between it and the population.

The dynamic structure of the Plan is a descriptive section of non-structural activities to be carried out in peacetime to prevent risk and prepare the community for the risk management, such as participatory planning, verification and periodic updating of the Plan, information, publicity and promotion of the Civil Protection culture and organization of exercises.

\section{Event and risk scenarios: a participatory approach in regional context}

\subsection{Event and risk scenarios}

To allow a more detailed analysis of the risk, based on the event dynamic defined on the geological, hydraulic, hydrologic and geomorphic characteristics of the environment in which water courses develop, the regional territory was divided by the type of the watercourse into 5 main contexts: water courses downstream of artificial reservoirs, river basins, ephemeral streams in karst environment, endorheic river systems and torrential streams.

The event scenario describes the characteristics of the awaited phenomenon, identifying the flooding areas, the phenomenon intensity and the singular points. Therefore, depending on the level of detail of the information derived from the analysis of existing sources and studies conducted on the area, in the Civil Protection Plan, there must be shown:

- characteristics of the hydrographic watershed;

- description of historical events with a focus on the forcing and related damage;

- event indicators with reference to the thresholds defined for the monitoring and warning system;

- flood prone areas;

- critical points where the process starts, transforms or changes direction, as well as the points where localized phenomena connected to specific situations are to be feared (construction sites, landfills, polluting sources, vegetation in the riverbed, etc.);

- observation points (direct or instrumented) from which it is possible to examine the event and monitor its dynamics, ongoing phenomena and evolution;

- location of the hydraulic structures.

The risk scenario is evaluated by overlapping the exposed elements and the flooding areas. In order to improve the management of Civil Protection actions, the Macro-areas of Risk (fig.2) have to be defined.

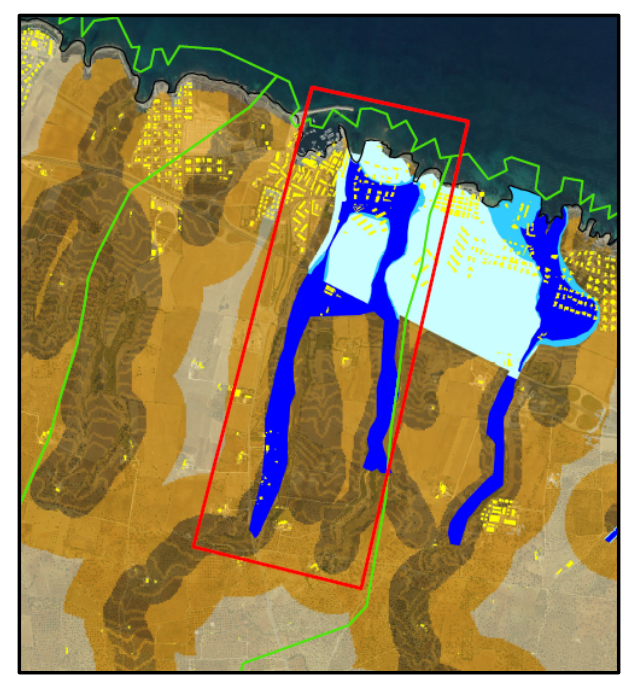

Figure 2. Example of Risk Macro-area in flood-prone areas 
This section of the plan has to be completed by the Risk Macro Area Sheets (fig.3), one for each defined macro area, in which to report the information relating to the hydrographic characteristics of the territory and to the population, buildings, infrastructures and exposed.

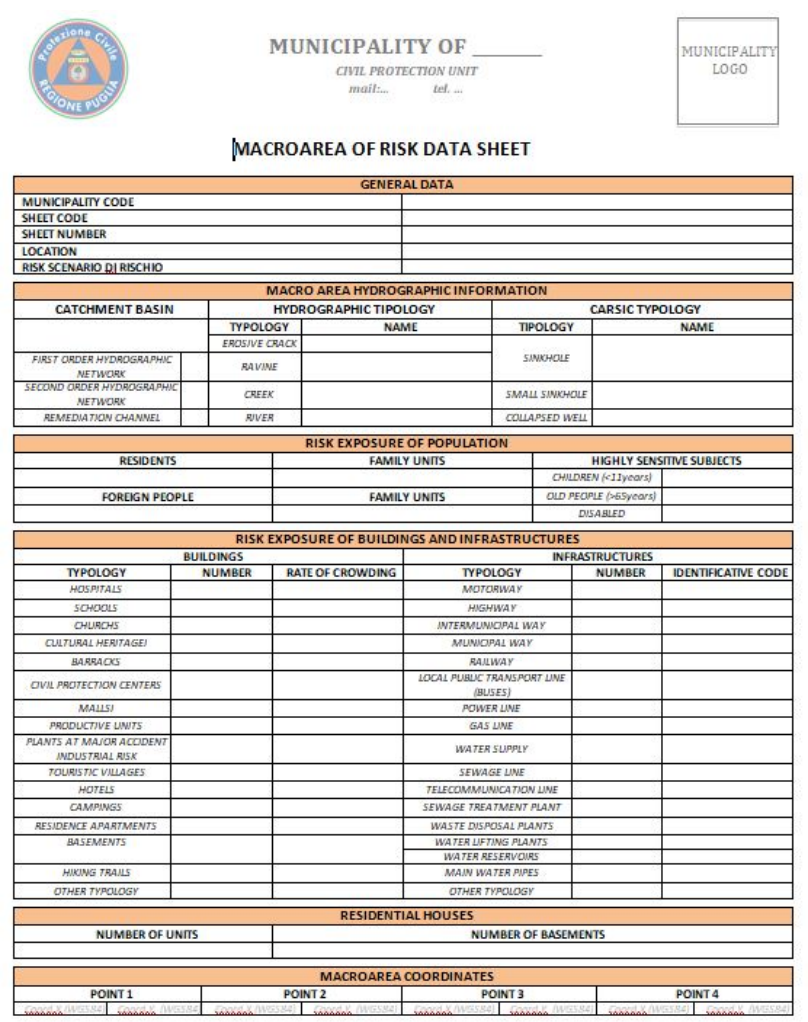

Figure 3. Risk Macro-area sheet

\subsection{The participatory approach}

In order to build Regional Guidelines calibrated to the real needs of the territory a representative Municipality for each context was selected to test the applicability of the tools and data sheets developed for the construction of event and risk scenarios, and to provide feedback and useful information to their definition.

The planned course included 3 collective meetings, held at the headquarters of the Civil Protection Section of Puglia, and 1 meeting held individually at the headquarters of each Municipality.

Some relevant topics emerged after the meetings:

- the widespread presence in the territory of poorly maintained canals representing a possible cause of flooding;

- the hydraulic behaviour of endorheic basins which show sudden flooding, in the days following the meteoric event, due to the spilling from karst sinkholes;

- the theme of excursions in flood-prone areas which, as they are not anthropized, may not be subject to the definition of risk scenarios. For this reason, the entry "hiking itineraries" has been included in the Macro- area risk sheet, in the section dedicated to the structures and infrastructures;

- the need of a procedure of early warning for avoid the presence of hikers during events;

- the presence of disabled people in tourist and accommodation facilities;

- the need of shared databases between the municipal offices (registry, social services, technical offices).

\section{The Organizational structure}

\subsection{The National Service}

The National Service operates according to the subsidiarity principle at central, regional and local level through the civil protection authorities which are: the President of the Council of Ministers as a national authority, the Presidents of the Regions and the Autonomous Provinces of Trento and Bolzano, the Mayors and Metropolitan Mayors as local territory authorities. When the Municipality cannot cope with the event, the Province, the Prefecture and the Region provide their support. In case of a national scale emergency the State is called to intervene.

The National Department develops and organizes national plans for risk scenarios and organizes exercises/drills, coordinates the intervention of the National Service in case of national emergencies, and promotes activities of risk forecasting and prevention. Also, it coordinates the participation of the National Service in European Union civil protection policies and its intervention in disaster relief operations abroad. The operating structures working in coordination with the National Service are shown in figure 4.

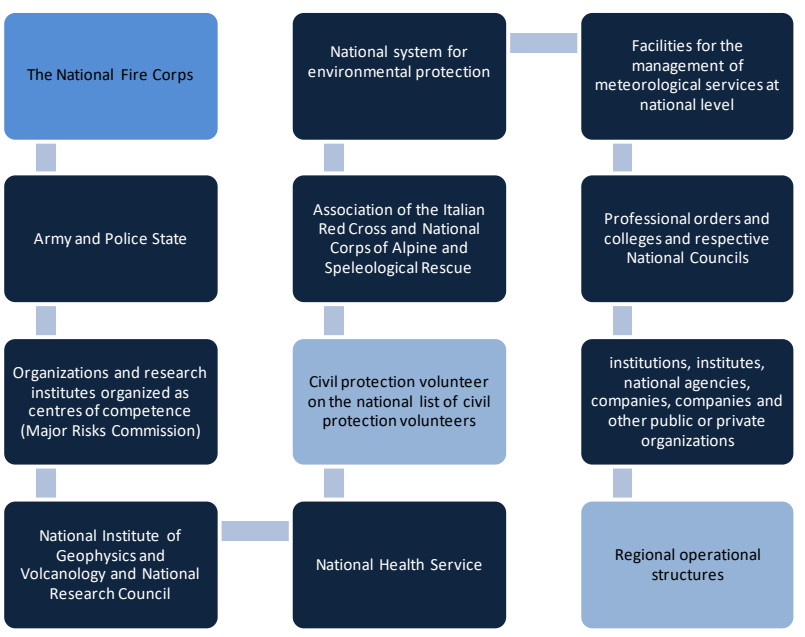

Figure 4. Civil Protection Operating Structures

\subsection{The Regional Service}

The Regional Service is constituted by:

- The Functional Centre (CFD) that provides for forecast, real-time monitoring, surveillance of events and alerting of the civil protection structures, evaluate 
the evolution of risk scenarios, manages the instrumental monitoring networks as well as carries out activities related to operational hydrology (flow measurement campaigns, definition of runoff scales, forecasting modelling);

- The Integrated Regional Operations Room (SOIR) is the site's technical command, communications and control, which is constantly able to initiate the appropriate response procedures and contrast the onset of emergencies or in view of the risk of an emergency, according to requests for assistance received or reports concerning the territory.

- The Regional Mobile Column is made up of vehicles, equipment and teams operating in emergency, in order to guarantee, with indispensable promptness and efficiency, an adequate response to both critical situations at the local level and to major disasters affecting the entire regional territory.

- The Volunteer office that coordinates the human resources of the Voluntary Organizations / municipal Groups registered in the Regional List and equipped with suitable means, volunteers with adequate training as well as Personal Protective Equipment.

- The Post Emergency office that deals with the states of emergency and consequent activities.

- The Prevention Office that adopts the regional civil protection plan and addresses for the preparation, review and periodic assessment of provincial and municipal plans.

\subsection{The Municipal Service}

The Mayor is the primary civil protection authority within the municipality and thus responsible for planning, rescue operations and information to the population on risk scenarios. He ensures the constant updating of the flow of information with the Prefect and the President of the Regional Council.

In case of concrete emergencies, coordination and operational activities are carried out through the Municipal Operational Centres (C.O.C.) that is organized in Support Functions as shown in figure 5.

The territorial presidium has the task of carrying out reconnaissance and site inspection activities in areas exposed to risk in peacetime, during the alert and event phase by monitoring the singular points identified in the Civil Protection Plan.

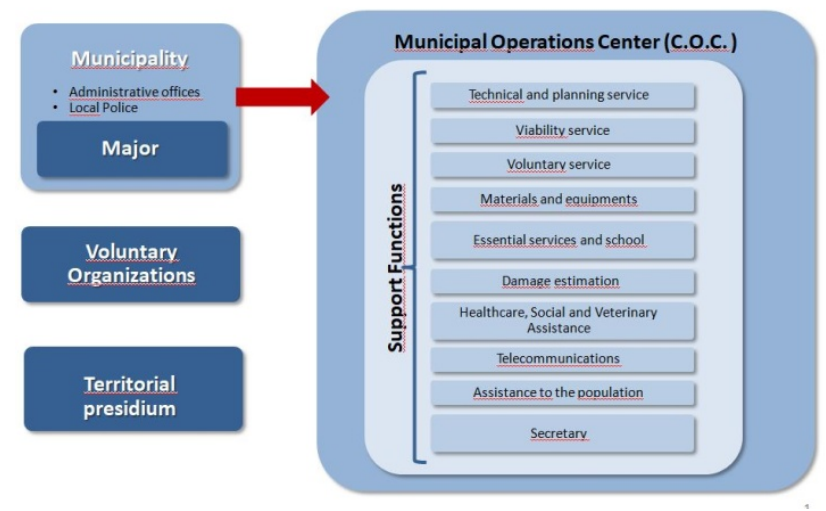

Figure 5. The Municipal Civil Protection Service

The Municipal Civil Protection Plan must identify in advance the Emergency Areas that are places for the reception of the affected population and for the massing of the rescuers and the resources necessary for overcoming the emergency.

In an intervention scenario, having a reliable communication system is strategic for the correct and adequate transfer of information between system components and other operating structures.

\section{The Intervention Model}

The Intervention Model assigns responsibilities in the command and control levels for emergency managing. Il enables a regular information exchange within the Civil Protection system.

It is a complex of procedures which codifies in sequence the actions to be performed, in logical and temporal order, as indicated below:

- activation of the operational phase;

- activation of the command and control system;

- $\quad$ verification of the current situation;

- $\quad$ issue of provisions.

For each risk and at the alert levels (yellow, orange, red) declared by the regional Civil Protection, the Mayor has to activate an operational phase (attention, pre-alarm, alarm). The operational phases identify the main Civil Protection activities to be implemented that can be outlined as attention=check, pre-alarm=act, alarm $=$ strengthen.

The main output of the intervention model is the cartography that must contain the map of the risk scenario and the map of the strategic resources of the Local Civil Protection System.

\section{The Dynamic structure of the Plan}

The Municipal Civil Protection Plan must be a current and updated tool with reference to territorial, environmental, administrative and personnel changes. Furthermore, it must include all the initiatives and strategies aimed at promoting the resilience of communities and the adoption of aware behaviours and self-protection measures by citizens.

For this reason, the structure of the Plan must be dynamic and it cannot be treated as a static document which, once drawn up, should be consulted only when necessary. The validity of the information and procedures contained therein must be constantly checked, the functionality of the flow of communication and information between the subjects involved in the Civil Protection activities and coordination with the other territorial strategic planning areas and the Plans and Programs must be guaranteed. The activities to be carried out are, on the one hand, the updating of the Plan and its constant functionality and, on the other, the dissemination of the knowledge and culture of Civil Protection and information to the population on the scenarios. 


\section{The IT tool for Civil Protection Plan implementation}

The S.IN.A.P.S.I. NetRisk system is an Emergency Planning and Management System of the Civil Protection Section of the Puglia Region which has the dual objective of creating a modern regional civil protection information system for emergency planning, monitoring and management, and coordinating activities for the management of the main types of risk in the Region (fire risk, weather-hydrogeological risk, hydraulic risk, seismic risk and industrial chemical risk).

One of the main tool of the platform is the Geographic Information System (GIS) for collection and archiving municipal civil protection plan data in a single optimized database. This GIS is integrated in a web application that collects, processes, manages and delivers data regarding emergency plan (infrastructures, risks, intervention methods, organizations) integrating them in an "intelligent" way. The creation of an information system based on updated data is the focus point on which the solution is built. In the elaboration of territorial databases is clear that it is essential to have geographic layer (numerical technical cartography, thematic, cadastral, digital orthophotos, digital terrain models) and databases (population, risk areas, infrastructures, etc.) updated in order to have a framework complete cognitive on which to contextualize the intervention and action domains (fig.6).

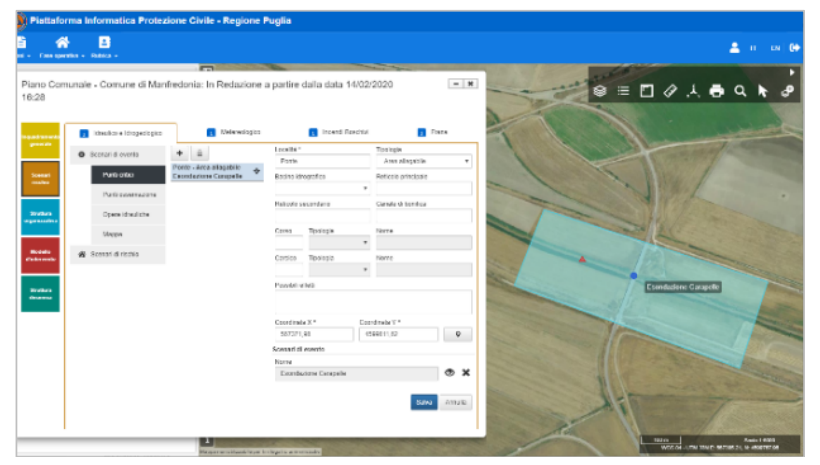

Figure 6. Geographic Information System

The integration of information allows for a unified centralized view and at the same time to face the problems related to territory management in an organic and joint way, increasing safety, efficiency and communication to improve quality of life and security. Aim of the implemented solution is to create a user-friendly web interface (fig. 7) to help municipal operators in filling out information about five-macro emergency plan section:

- General overview: legislation, territorial overview, relevant historical events;

- Risks: risk and event scenarios;

- Organizational structure: contacts, roles, support functions;

- Intervention model: operational state, subjects, actions;

- Other information: attachments and dynamics data.

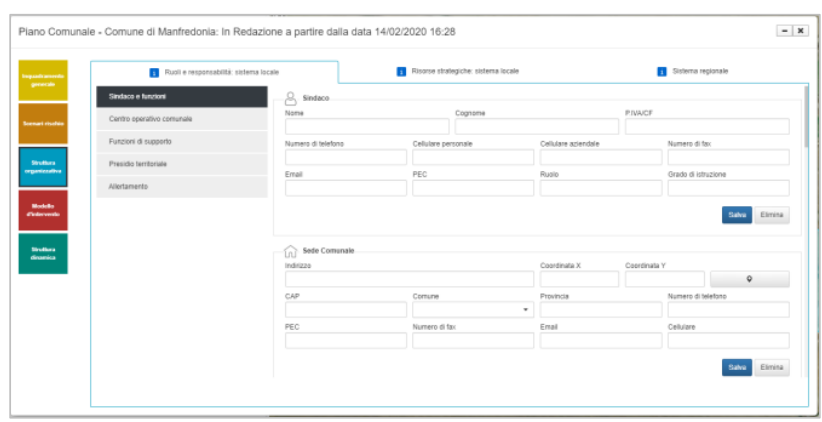

Figure 7. Emergency plan sheet

Compilation is supported by the use of geographic tools for editing information directly on the map. GIS focus on possibility of deriving and analyzing the relationship that a layer may have with other layers. It is important to recognize that territory mapping shows the interdependencies of various layers in order to integrate them spatially and take more support information. The specific physical objects that are of interest for the application include critical point, observation point, river basins, streams, flood, orthophoto, administrative boundaries, etc. Derived information is deduced or determined through analysis of these basic layers using an intelligent decision support system integrated in the application. Decision-support environment allows a number of "what-if" type questions to be asked and answered and gives operators the possibility to understand territory site classification (fig.8).

The implemented web application and the integrated GIS permits to define an event scenario, that characterizes the evolution of an expected event and to define the vulnerable points (buildings and infrastructures) that may be affected by the event itself. When a macro risk area is defined (drawing it or uploading a shapefile), automatically the event scenarios are associated and the system lists the infrastructures and the critical points within.

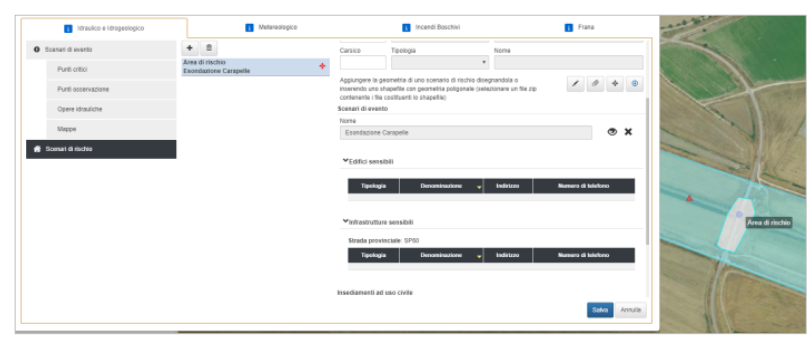

Figure 8. Automatic data elaboration

The ultimate goal of the information is to collect all the information relating to municipal emergency plans in a single unified database, and GIS is the perfect technological tool to facilitate authorities in achieving this goal.

In this way individual municipality can have all content of the emergency plan (both territorial and alphanumeric) quickly and promptly by means of appropriate interrogation and search functions. 
To complete the main management functions of the emergency plan, the application offers tools to the users that allow them to easily update the different sections of the plan, to store the chronology of the changes made, to print the plan or sections of it.

In the same way, having the information of the emergency plans of all the municipalities of the Puglia Region in a single format, allows regional Civil Protection operators to have a uniform picture of the territory and information of the various plans that can be compared with each other.

Emergency plan database is the operational support to which the Regional Civil Protection refers to manage the emergency with the highest level of effectiveness.

\section{References}

1. Regional Law No. 53 of dicembre 12 (2019). Regional Civil Protection System. http://www.regione.puglia.it/documents.

2. Regional Council Decision No. 1414 of July 30 (2019). Regional Guidelines for Municipal Civil Protection Plan.

http://www.regione.puglia.it/documents.

3. Legislative Decree No. 1 of January 2 (2018). Civil protection code. http://www.protezionecivile.gov.it

4. Italy - Disaster management structure Vademecum Civil Protection. https://ec.europa.eu/echo/files/civil protection/vade mecum/it/2-it-1.html

5. PON Governance 14/20. Program to support the strengthening of governance regarding the reduction of hydrogeological and hydraulic risk for civil protection purposes.

http://www.pongovernance1420.gov.it/en/

6. Alexander, D. E. (2016). How to Write an Emergency Plan. Edinburgh and London: Dunedin Academic Press.

7. C2-SENSE (2014). Project Title: Interoperability Profiles for Command/Control Systems and Sensor Systems in Emergency Management. https://c2sense.eu/wp-content/uploads/2015/12/D71.pdf

8. Ronco, F., Lafortezza, R., Colangelo, G., Elia, M. and Sanesi, G. (2010). Analisi della incidenza degli incendi boschivi in aree di interfaccia: un caso di studio in Puglia. Conference proceedings $14 a$ Conferenza Nazionale ASITA - Brescia 9-12 novembre 2010. http://atti.asita.it/ASITA2010/Pdf/072.pdf

9. Gentile, F., Bisantino T. and Trisorio Liuzzi G. (2008). Debris flow risk analysis in south Gargano watersheds (southern-Italy). Natural Hazards, 44(1): $1-17$.

10. Legislative Decree No. 112 of March 31 (1998). Conferimento di funzioni dello stato alle regioni ed agli enti locali. Gazzetta ufficiale no. 92, 21 April 1998.

http://www.protezionecivile.gov.it/resources/cms/do cuments/Dlgs_112_1998.pdf 